\title{
A CARBONIZAÇÃO CONTINUA - CARBOVAL E A COGERAÇÃO DE ENERGIA*
}

Fernando Lopes Latorre ${ }^{1}$ Fabiano Mendes ${ }^{2}$ Lis Soares ${ }^{3}$

Ronaldo Sampaio

\section{Resumo}

A cadeia produtiva do carvão vegetal que envolve as etapas de silvicultura, colheita e carbonização, tem passado por diversas mudanças nas últimas décadas. As produtividades volumétricas das florestas de eucalipto no Brasil aumentaram cerca de 4 vezes nos últimos 50 anos. A colheita florestal, nesse mesmo período, partiu de formas extremamente primitivas para máquinas de alta produtividade. Os processos de carbonização também evoluíram, mas sempre no sentido de aumento de produtividade dos fornos, com perda na qualidade do carvão vegetal produzido e sem aproveitamento integral da energia contida na madeira. Nesse contexto, esta etapa do processo chega a seus limites tecnológicos, ambientais e econômicos, ameaçando a sua sustentabilidade. Buscando resolver esse impasse, a Vallourec estudou o processo Lambiotte como base tecnológica para desenvolver seu ambicioso projeto de carbonização contínua com cogeração de energia em substituição ao processo artesanal de fornos retangulares de batelada. Esta tecnologia após vários anos de desenvolvimento demonstrou sua plena capacidade para atender a todos os aspectos demandados atualmente.

Palavras-chave: Carbonização Contínua; Processo Lambiotte; Carvão Vegetal.

\section{CONTINUOUS CARBONIZATION - CARBOVAL AND ENERGY COGENERATION Abstract}

The charcoal production chain, that involves the silviculture, harvesting and carbonization steps, has passed through several changes in the last decades. The average volumetric yields of eucalyptus forests in Brazil increased about 4 times in the last 50 years. The forest harvesting, in this same period, started from extremely primitive forms for machines of high productivity. The carbonization processes also evolved, but always in the way of increasing the productivity of the kilns, resulting in loss of charcoal quality and without the full use of the wood energy. Therefore, this step of the process reaches its technological, environmental and economic limits, threatening its sustainability. In order to solve this impasse, Vallourec studied the Lambiotte process as a technological base to develop its ambitious continuous carbonization project with energy cogeneration, replacing the conventional processes of rectangular batch kilns. This technology after several years of development has demonstrated its full capacity, to meet all the required aspects today.

Keywords: Continuous Carbonization; Lambiotte Process; Charcoal

\footnotetext{
Engenheiro Metalúrgico, Gerente Projeto Carboval, VFL, Curvelo, MG, Brasil.

Engenheiro Metalúrgico, Engenheiro, VFL, Curvelo, MG, Brasil.

3 Engenheira Mecânica, Dra., Engenheira Especialista Sênior, Vallourec Soluções Tubulares do Brasil S.A

4 Engenheiro Metalúrgico,M.Sc., Ph.D, Consultor, RSConsultants Ltda
} 


\section{INTRODUÇÃO}

As tecnologias convencionais de produção de carvão vegetal em fornos de alvenaria (tijolos e barro), que apesar de serem responsáveis pela quase totalidade da produção atual, atingiram seu limite para atender às novas demandas competitivas que garantirão a sustentabilidade da indústria siderúrgica a base de carvão vegetal.

As inúmeras melhorias que aconteceram nestes fornos, nos últimos anos, sempre estiveram relacionadas à produtividade, com aumento do tamanho dos fornos, de maior mecanização das operações de corte de madeira, do manuseio e secagem natural no campo e no transporte das lenhas para serem, mecanicamente, carregadas nos fornos de alvenaria. Também aconteceram esforços com a introdução de sensores de temperatura para auxílio aos carbonizadores, no controle do ritmo das etapas da carbonização.

Apesar desses investimentos terem reduzido os custos da produção de carvão bruto, a qualidade do carvão vegetal caminhou no sentido contrário, com o aumento da fração fina $(<10 \mathrm{~mm}$ ) não utilizada no topo dos altos fornos e aumento das cinzas do carvão.

Nesse contexto, a Vallourec buscou uma tecnologia que representasse uma mudança no patamar tecnológico para produção de carvão em fornos de alvenaria, com controle artesanal, para fornos industriais, representado pela tecnologia de Carbonização Contínua Carboval.

As principais características perseguidas no desenvolvimento do processo Carboval foram:

- Utilizar as florestas de clones de Eucalyptus existentes e obter um carvão vegetal homogêneo, livre de contaminações e com sua fração granular maior que a obtida pelos reatores artesanais de alvenaria;

- Desenvolver novas biomassas através do conhecimento das inúmeras influências destas nas etapas da carbonização e na qualidade do carvão vegetal. Esta etapa é possível em uma tecnologia que permita o controle da pirólise;

- Reduzir os custos de manuseio e logística da madeira da floresta em pé até o site de carbonização, com utilização de tecnologias acessórias de maior produtividade e automação;

- Secar os toretes de madeira até a umidade de controle, nas unidades de carbonização, com uso do calor sensível dos gases de exaustão completamente combustos do reator de carbonização, reduzindo o tempo de secagem necessário dos processos artesanais;

- Resfriar o carvão vegetal produzido em ambiente protegido de contaminações do solo e com o teor de umidade necessário ao seu equilíbrio com a umidade relativa do ambiente de sua utilização; 
- Utilização da energia excedente da madeira, na forma de bio-óleo e os demais resíduos florestais com conteúdo energético, tais como galhos, cascas e folhas para termogeração, gerando uma receita adicional e uma expressiva redução de custos.

\section{PANORAMA ATUAL DA PRODUÇÃO DE CARVÃO VEGETAL}

A produção de carvão vegetal para fins siderúrgicos através da utilização de florestas plantadas envolve uma cadeia com diversas etapas que vão desde a escolha da matéria prima a ser plantada até a expedição do carvão vegetal para as unidades de consumo.

As florestas do gênero dos Eucalyptus devido a sua rusticidade, produtividade e às características da madeira, são uma das melhores opções para a produção de carvão vegetal. Reflorestamentos de eucalipto, planejados e manejados adequadamente, produzem árvores de troncos retos, uniformes e madeira com densidade adequada para a obtenção de carvão de boa qualidade (PINHEIRO et al., 2006).

Além do uso para fins energéticos, o eucalipto possui diversos outros fins, como mostrados na Figura 1, correspondendo a 72,0\% dos cerca de 7,6 milhões de hectares de florestas plantadas no Brasil (IBÁ, 2014).

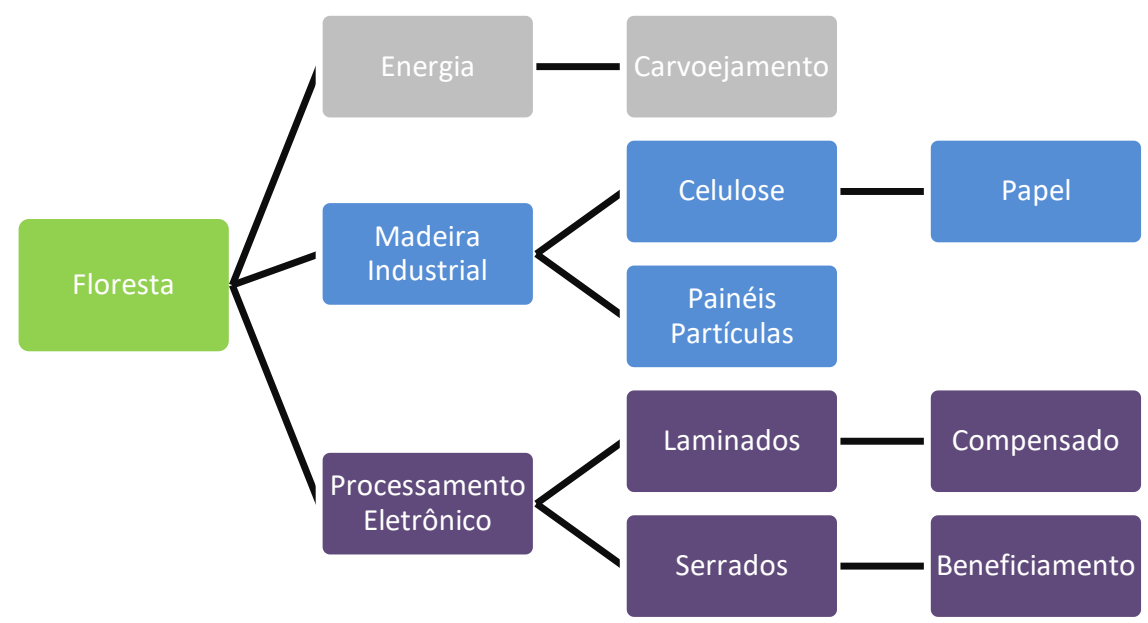

Figura 1 - Aplicações possíveis para a madeira.

Em virtude dessa ampla utilização, diversas melhorias aconteceram nos processos de silvicultura e colheita florestal.

$\mathrm{Na}$ silvicultura, os significativos investimentos em pesquisa e desenvolvimento, buscando a melhoria genética dos plantios voltada para produtividade e do aprimoramento de técnicas de manejo florestal em atividades como nutrição florestal, controle de pragas, dentre outros, fizeram com que houvesse um aumento significativo de produtividade volumétrica ao longo das últimas décadas, conforme Figura 2 (IBÁ, 2014). 


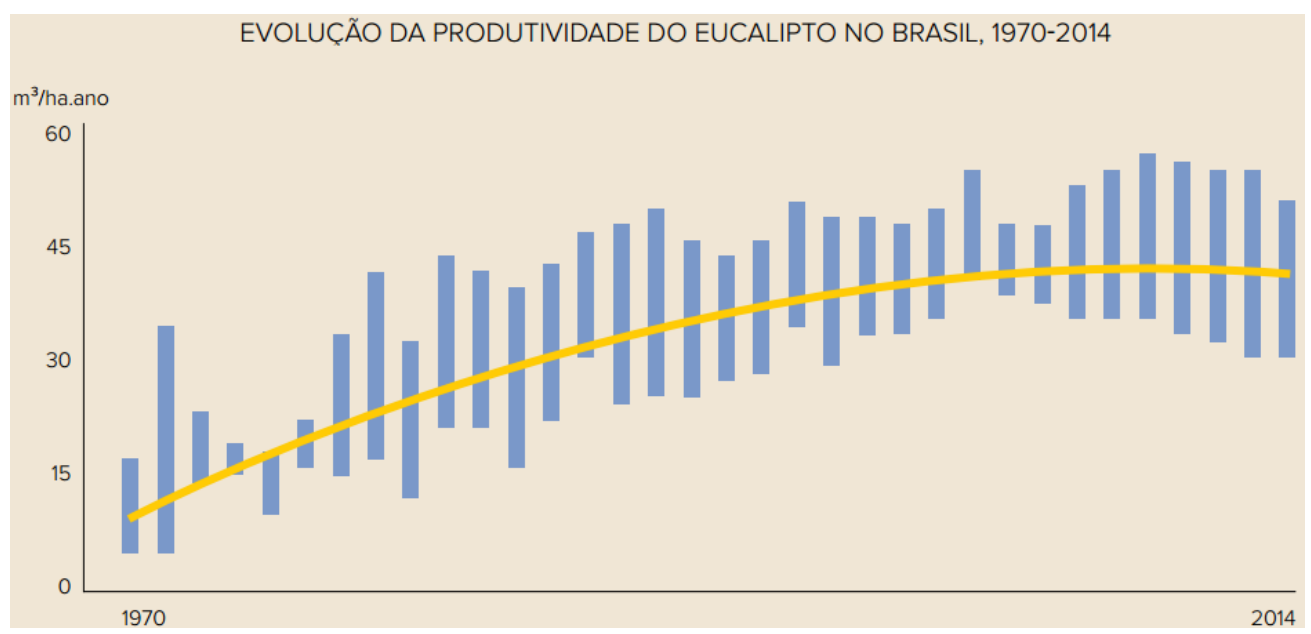

Figura 2 - Evolução da produtividade volumétrica do Gênero Eucalyptus no Brasil.

Apesar do expressivo aumento na produtividade florestal volumétrica, a densidade, que é uma das principais características da madeira para produção de energia, carvão vegetal siderúrgico, não acompanhou este aumento volumétrico, Figura 3. Dessa forma, apesar de ganhos na produtividade florestal em volume, a madeira perdeu qualidade para produção de carvão vegetal siderúrgico ao longo do tempo.
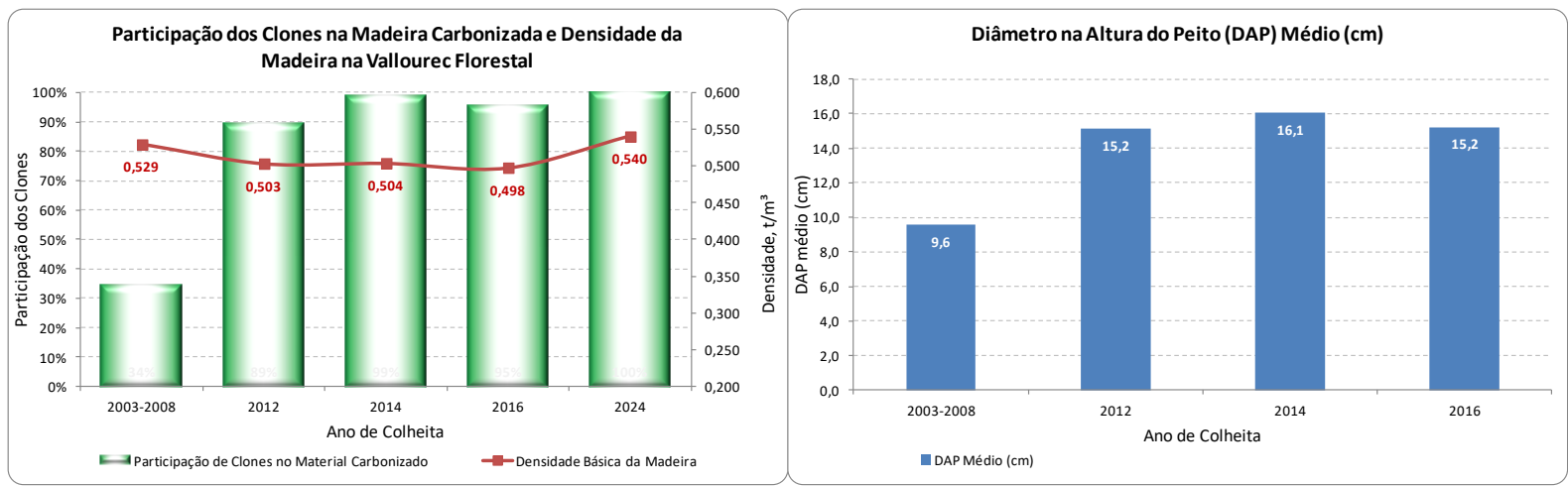

Figura 3 - Evolução da densidade da madeira ao longo do tempo

Outro aspecto importante do ganho de produtividade volumétrica foi que este trouxe o incremento do diâmetro das florestas. A umidade da madeira é um dos pontos principais do gasto energético na produção e no controle da qualidade do carvão vegetal. $O$ incremento do diâmetro basal das florestas dificultou a secagem da madeira, alongando o tempo de secagem no campo.

$\mathrm{Na}$ colheita florestal e logística de transporte de madeira, as grandes mudanças vieram em virtude da mecanização das atividades. Como é possível observar na Figura 4, as etapas de corte evoluíram para o feller buncher, equipamento com alta produtividade. O transporte de madeira, por sua vez, avançou do uso de animais para caminhões com alta capacidade. Nestas etapas o aumento da produtividade das florestas também trouxe ganhos significativos com redução dos custos do volume de madeira entregue no site de carbonização. 


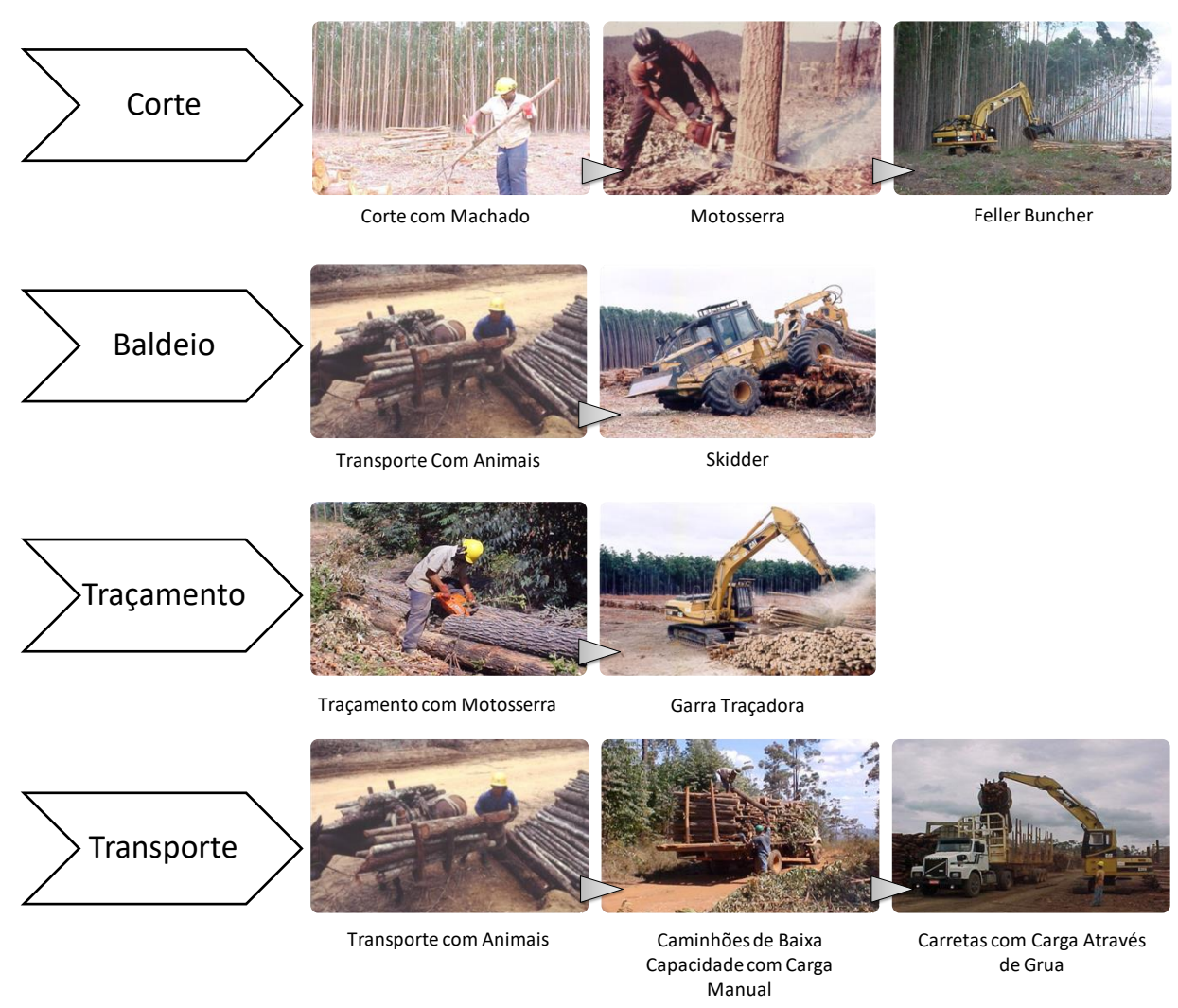

Figura 4 - Evolução tecnológica da colheita florestal e logística de madeira.

Após preparada e transportada para os sites de carbonização, a madeira é enfornada e transformada em carvão nos fornos. Assim como nas outras etapas, nesta parte da cadeia também houve diversas melhorias com a mecanização.

Os fornos de carbonização permaneceram de alvenaria em virtude dos baixos investimentos. Estes aumentaram sua escala com diferença na capacidade de produção por batelada em até 100 vezes. Para viabilizar este aumento de escala, as operações de carga e descarga da madeira, que nos fornos circulares são manuais, passaram a ser mecanizadas. Para esta mudança foi necessário uma adequação no formato dos fornos e na forma de carregamento. Os fornos, que até então possuíam uma base circular e enfornamento de madeira na direção base topo (em pé), passaram a ter base retangular com carga na horizontal (deitada). A adaptação dos fornos a carga mecanizada trouxe ganhos de produtividade na colheita com o aumento do comprimento da madeira. Por outro lado, a madeira de maior comprimento e na posição horizontal trouxe mudanças desfavoráveis na qualidade do carvão.

A descarga do carvão também passou a ser mecanizada com utilização dos mesmos equipamentos que realizam a carga. Os fornos de alvenaria mantém parte de sua produção por ciclo de madeira não carbonizada (tiço) na região inferior. $\mathrm{Na}$ descarga do carvão é realizada a retirada destas frações e o empilhamento do carvão nas praças para estabilização. Esta mecanização da descarga trouxe reflexos negativos na qualidade do carvão, principalmente com o aumento na geração de finos pela intensa movimentação do carvão e contaminação com o solo que eleva o percentual de cinzas. 
Apesar de mudanças significativas no tamanho dos fornos, o conceito de carbonização não passou por alteração expressiva. Com exceção da ignição, que em alguns modelos passou a ser realizada através de câmaras (duto situado abaixo do piso do forno onde são colocados toras de tiço para ignição), o fornecimento de energia sempre foi feito pela queima parcial da madeira com ação manual do carbonizador, verdadeiro artesão. Esta queima é responsável pela geração de gases quentes que irão trocar calor, por condução e convecção, com o restante da carga. $\mathrm{Na}$ Figura 5, é possível observar as alterações tecnológicas que ocorreram nestes fornos.

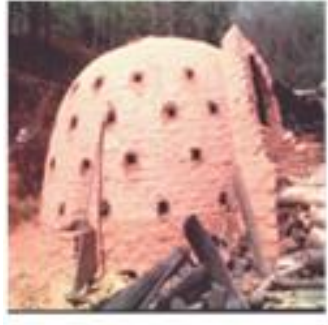

Rabo Quente

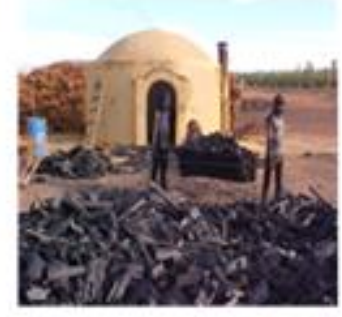

Circulares

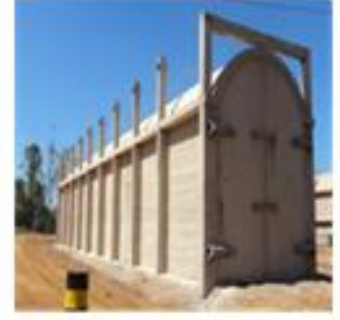

Retangulares

Capacidade: $150 \mathrm{t}$ de madeira

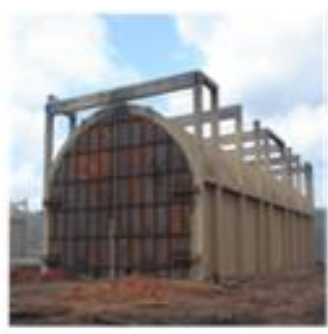

Retangulares Capacidade: $300 \mathrm{t}$ de madeira

Figura 5 - Evolução tecnológica dos fornos de alvenaria.

Como o processo é altamente heterogêneo, com diversos estágios da carbonização acontecendo ao mesmo tempo no interior do forno, há uma alta variação na composição dos gases liberados pela chaminé dos fornos durante cada instante do processo de carbonização. Além da heterogeneidade que acontece no tempo instantâneo, há a heterogeneidade inerente ao processo de transformação química da madeira ocorrendo em um forno de batelada, ou seja, no início do ciclo há uma grande liberação de água durante a secagem da madeira, no final há uma maior concentração de gases condensáveis e não condensáveis. Esta variação de composição dos gases nos teores de água e gases combustíveis ao longo da carbonização dificulta a utilização destes em processos de queima, principalmente quando se necessita de estabilidade de chama e aporte de energia como em processos de cogeração de energia. Mesmo com vários fornos em estágios diferentes interligados a uma fornalha, o impacto da heterogeneidade atribuído aos diferentes estágios é reduzido, mas as mudanças instantâneas na composição dos gases associadas à disposição da ignição e da madeira no interior do forno trazem instabilidades que, praticamente, inviabilizam a cogeração.

No que diz respeito ao controle de processo, diversos esforços têm sido empregados na melhoria do controle de temperatura de carbonização, uma vez que este parâmetro está diretamente ligado à eficiência de conversão de madeira e carvão. O setor tem buscado prever o comportamento ideal de cada batelada através da instalação de termopares e modelamento de curvas de processo (temperatura vs. tempo), que relacionam parâmetros, tais como umidade, densidade e diâmetro da madeira. Este esforço tem efeito limitado, devido ao baixo controle no fornecimento de energia ao processo e aos materiais construtivos usados nesta tecnologia (alvenaria).

Entretanto, o aumento do volume dos fornos, principalmente a altura, para permitir a mecanização da carga e descarga, levou a maiores diferença físicas e químicas do 
carvão ao longo do eixo vertical do forno. Estes fornos acentuaram os desvios de qualidade do carvão. Estes desvios trazem como consequências o término da carbonização ocorrendo nos processos metalúrgicos subsequentes e implicam em dificuldade no controle térmico dos reatores metalúrgicos.

Esta variabilidade intrínseca aos processos convencionais traz impactos na mensuração do rendimento gravimétrico. A alta heterogeneidade na composição química, acrescido de contaminações e da alta higroscopicidade do carvão produzido, aumentam as incertezas associadas à medição, de tal forma que se torna inviável obter um valor de rendimento gravimétrico confiável. Como esse parâmetro é de alta sensibilidade e impacto nos custos produtivos, a busca da melhor qualidade do carvão relacionada a este indicador fica prejudicada.

Outro ponto é o desenvolvimento da biomassa para energia. A heterogeneidade do carvão produzido nos fornos de alvenaria retardou a identificação dos principais parâmetros que interferem na produtividade e qualidade do carvão na etapa da carbonização. Os dados de laboratório não se reproduzem na escala operacional, o que dificultou os avanços das biomassas direcionadas ao setor energético.

Dessa forma, os ganhos de escala, que apesar de aumentarem a produtividade volumétrica das florestas e reduzirem os custos de produção do carvão vegetal bruto, não trouxeram os ganhos esperados de qualidade e com o aumento dos investimentos em máquinas e fornos, esta tecnologia chega ao limite econômico tecnológico. Este cenário muda com os conhecimentos adquiridos com a carbonização continua Carboval permitindo avanços nos reatores metalúrgicos.

\section{A TECNOLOGIA CARBOVAL DE PRODUÇÃO DE CARVÃO VEGETAL}

Diante do cenário citado anteriormente, a Vallourec buscou desenvolver uma tecnologia que representasse uma brusca ruptura nos modos convencionais de produzir carvão vegetal siderúrgico o que resultou na Carboval.

A Tecnologia Carboval representou um progresso significativo na forma de produzir carvão. Neste sistema, todas as etapas, desde a preparação da madeira até a expedição do produto final, foram desenvolvidas e conjugadas de modo a se obter o máximo de eficiência possível. Este aumento de eficiência é convertido em redução de custos operacionais, melhor qualidade do produto e melhoria nas condições ambientais e laborais. Nas Figuras 6.a e 6.b são mostradas uma fotografia da planta piloto instalada na Vallourec e o fluxo de sólidos e gases nesta.

As etapas do Sistema Integrado Carboval de Produção de Carvão Vegetal, que vai desde o plantio de florestas até expedição do carvão vegetal, são mostradas na Figura 7.

Nesta unidade industrial, após o recebimento da madeira já processada em picadores, têm-se as seguintes operações que acontecem em sequência: 

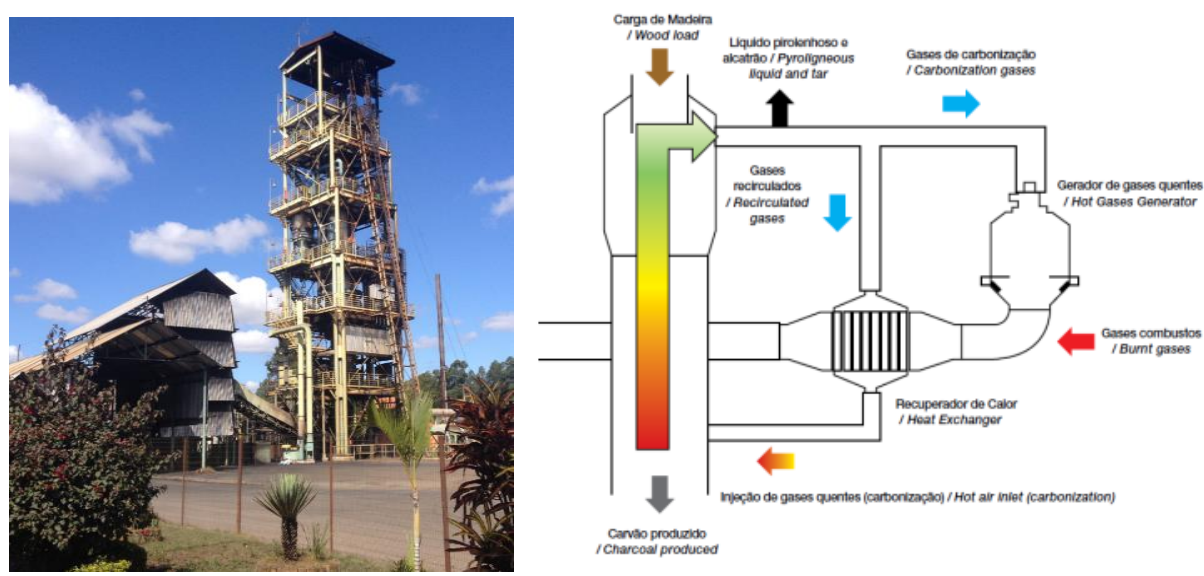

Figura 6.a (esquerda) - o reator de carbonização contínua Carboval. Figura 6.b (direita) - Fluxo de sólidos e gases na Tecnologia Carboval.

1- Secagem dos toretes a níveis de umidade da ordem de até $30 \%$ em base seca;

2- Carbonização no forno com resfriamento primário no interior do mesmo;

3- Resfriamento secundário, em que é feita a passivação do carvão vegetal em silos externos que também armazenam o carvão vegetal para o carregamento por gravidade nos caminhões que o levam para a siderúrgica e garantem um carvão livre de impurezas.

Os resíduos florestais, que também são produtos da etapa de picagem, e os gases excedentes gerados na carbonização, geram energia numa unidade termoelétrica.

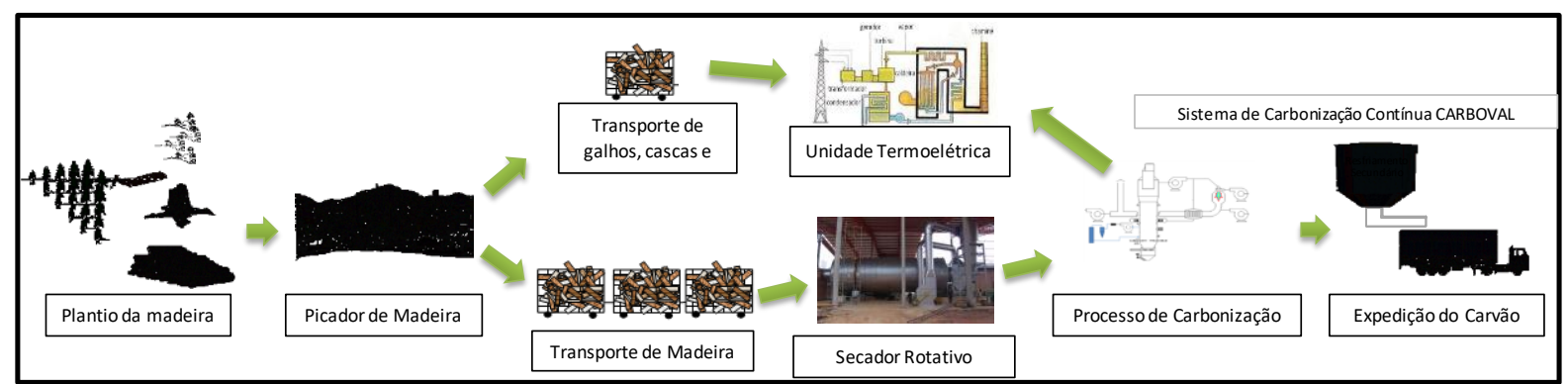

Figura 7 - Fluxo esquemático das etapas de produção de carvão no Sistema Carboval.

A árvore colhida é processada em um picador, que permite um melhor aproveitamento da floresta com o uso integral da mesma na cogeração de energia. A separação da fração de lenho picado das cascas, galhadas e folhas permite que estas sejam destinadas para processos de termogeração e só é viável financeiramente através da utilização de picadores. Os picadores são tecnologias consolidadas na indústria de processamento de biomassa para uso na produção de chips e após diversas melhorias foi desenvolvido um picador de peças com tamanho adequado para produção de carvão siderúrgico.

O picador permitiu obter madeira com tamanhos padronizados para carbonização e o próximo passo foi o controle da umidade desta madeira. Para tanto, um secador da madeira usando o calor sensível dos gases combustos da carbonização foi desenvolvido. 
Este secador controla o efeito negativo da umidade elevada da madeira principalmente em diâmetros superiores a $14 \mathrm{~cm}$. Com o controle da umidade elevamos a produtividade e a qualidade do carvão vegetal bem como reduzimos a demanda energética disponibilizando mais energia para cogeração.

O secador industrial permitiu a redução do tempo de secagem e consequentemente do estoque de madeira no campo em até 200 dias quando comparado ao forno de alvenaria. Este elevado tempo mínimo de estoque, nos fornos convencionais, ocorre em virtude do diâmetro da madeira, uma vez que toras de maior diâmetro, e consequentemente, maior umidade inicial, atingem a umidade objetivada em um tempo maior.

Estas restrições com o diâmetro basal das florestas foram estudadas e resolvidas com picadores de peças grandes entre 15 e $50 \mathrm{~cm}$. Todas as peças de madeira são padronizadas em termos dimensionais o que esta diretamente relacionada à granulometria do carvão. Também permitiu o uso das florestas atuais de maior diâmetro basal com mais eficiência e produzindo o carvão com a qualidade especificada.

Após preparada, a madeira que já está livre de impurezas, com tamanho padronizado e com umidade controlada é carregada no topo do reator Carboval. No interior do reator, a madeira desce por gravidade, e troca calor com um fluxo de gases ascendente, com taxa de aquecimento constante. As etapas do processo são a secagem completa (retirada da umidade residual), seguida da degradação das holoceluloses. Quanto maior a temperatura na metade inferior da zona de carbonização, maior será a degradação da celulose e de parte da lignina, com a evaporação do alcatrão e fixação de carbono encerrando a pirólise da madeira. A energia necessária ao processo é fornecida pelo próprio gás gerado na pirólise da madeira e por uma massa de gás recirculante aquecido na temperatura de carbonização desejada. Este fluxo recirculante de gás é injetado na base da zona de carbonização, Figura 8.

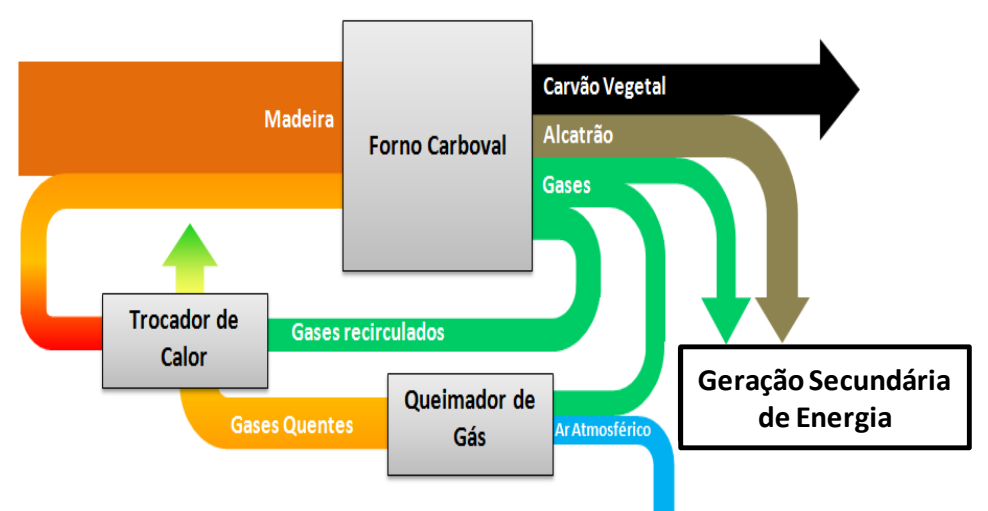

Figura 8: Fluxo de materiais no processo Carboval.

Um exemplo de comportamento real do perfil térmico do forno, onde cada linha corresponde a um termopar em posição equivalente à torre ao lado do gráfico é mostrado na Figura 9. Nesta, nota-se que o perfil térmico do Forno Carboval é praticamente constante e com isotermas horizontais, o que implica que todas as peças de madeira sejam submetidas às mesmas condições de tempo e temperatura dentro do forno. 
A manutenção do perfil térmico constante é alcançada controlando-se a camada de madeira em pirólise, a recirculação da massa de gases aquecidos na temperatura desejada, a descarga do carvão na base do reator bem como a umidade da madeira carregada. Desta forma, é possível um domínio e acompanhamento completo sobre as principais variáveis da carbonização, o que torna possível um ajuste automatizado do processo.

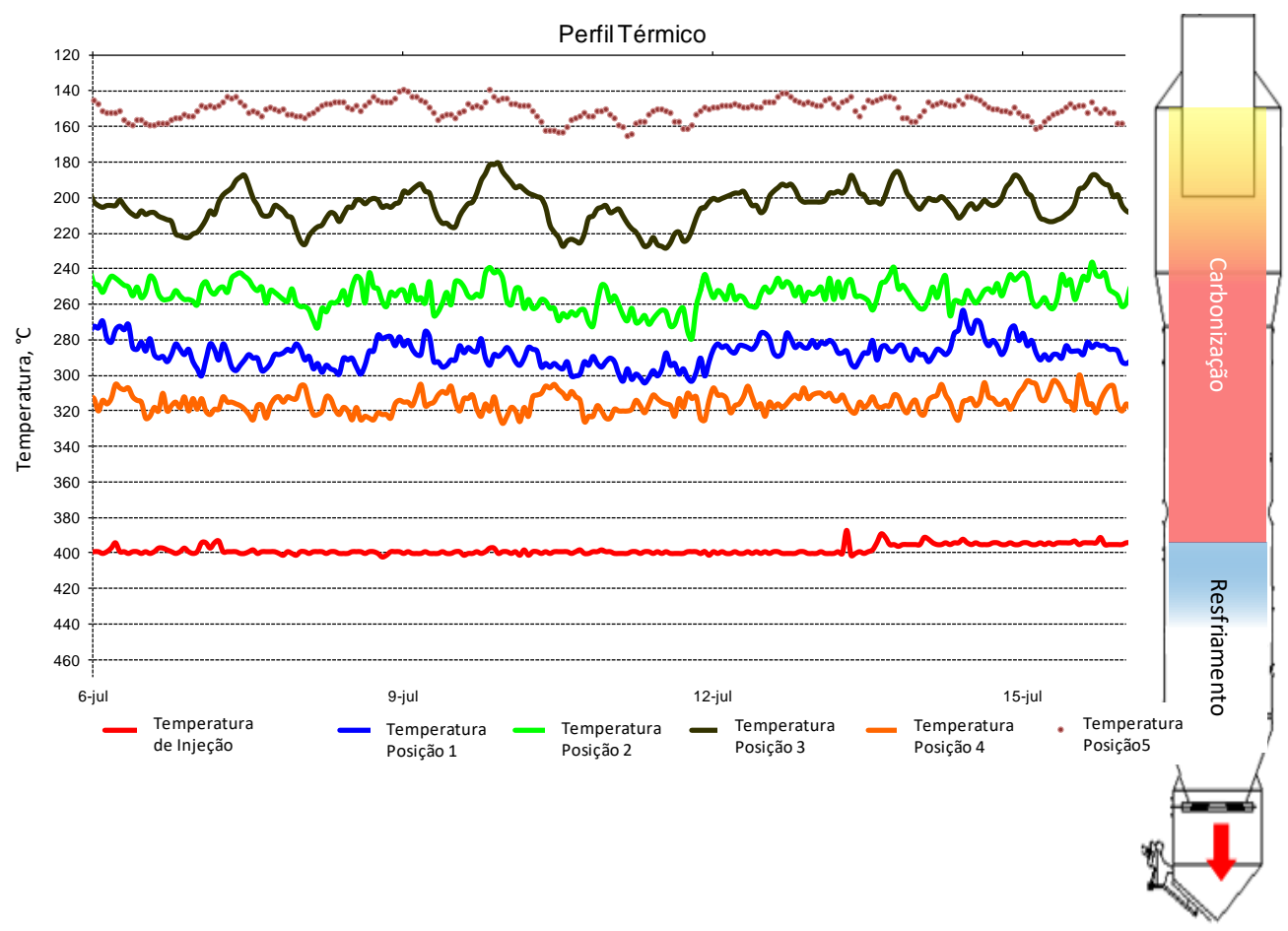

Figura 9 - Perfil Térmico do Forno de Carbonização Contínua (em escala invertida): As temperaturas crescem no sentido topo-base.

Como resultado deste controle de processo, tem-se o carvão dentro de uma faixa estreita de qualidade química (cinzas e carbono fixo) e de granulometria. Este fato implica em maior permeabilidade dos carvões em reatores metalúrgicos, conforme mostrado na Figura 10. Esta por sua vez é acompanhada de aumento de produtividade e redução do consumo específico de redutor dos reatores.

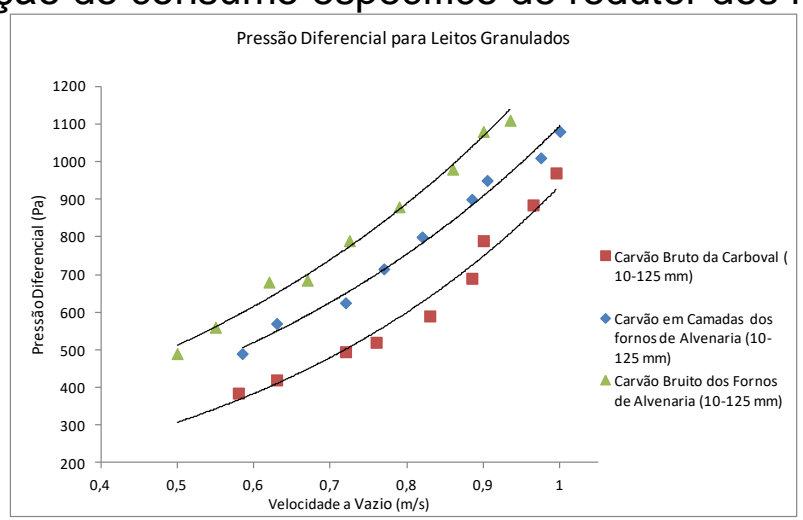

Figura 10 - Efeitos da baixa variabilidade de tamanho do carvão produzido.

O controle da carbonização obtido pela Carboval contribui para a pesquisa da nova geração de biomassa, pois podemos identificar as influencias da madeira na qualidade e rendimento do carvão vegetal. 
A tecnologia Carboval é considerada um processo $100 \%$ limpo e sustentável do ponto de vista ambiental uma vez que todo gás emitido é combusto, Figura 8. Todo o gás é composto de $\mathrm{N}_{2}, \mathrm{CO}_{2}$ e $\mathrm{H}_{2} \mathrm{O}$ e o $\mathrm{CO}_{2}$ gerado por fonte renovável não é considerado gás de efeito estufa (UNFCCC 2006).

\section{POTENCIAL DE APROVEITAMENTO DE ENERGIA NO SISTEMA CARBOVAL}

Os gases da pirólise produzido no Processo Carboval, possuem uma baixa variabilidade na composição química ao longo do tempo. O controle da umidade da madeira e das etapas da carbonização ao longo do tempo além do fato de todos os gases serem coletados no topo do reator (único local) viabilizam o emprego destes gases. Esta baixa variabilidade, permite a sua utilização em processos de termogeração, uma vez que a queima deste é estável e constante. Durante o desenvolvimento da Carboval, uma caldeira e gerador foram acoplados a planta piloto completando o desenvolvimento da tecnologia com a produção de energia através de um ciclo Rankine.

Visando avaliar o potencial energético desta tecnologia em escala industrial, realizou-se uma análise da distribuição de energia neste processo. Nesta, foram utilizadas informações reais da operação desta tecnologia. Utilizou-se como parâmetro no balanço um carbono fixo igual a $71 \%$ o que implicou em um rendimento gravimétrico igual a $42 \%$.

A Figura 11 mostra a distribuição de energia contida na madeira após a transformação em carvão. A Carboval produz um maior rendimento energético chegando a $63 \%$ na produção do carvão vegetal. Da energia restante, $6 \%$ é o aporte de energia necessário para a pirólise e $31 \%$ da energia total contida na madeira tem potencial de geração de energia elétrica.

A energia contida nos gases gerados no processo (condensáveis e não condensáveis), acrescido da energia na biomassa residual, que corresponde a uma fração de até $25 \%$ em massa da floresta, potencializa uma unidade geradora de energia elétrica que pode produzir até 1,6 MW.h/t carvão vegetal. Esta geração possível total fortalece os resultados sustentáveis desta tecnologia com redução expressiva de custos através da receita com venda de energia elétrica.
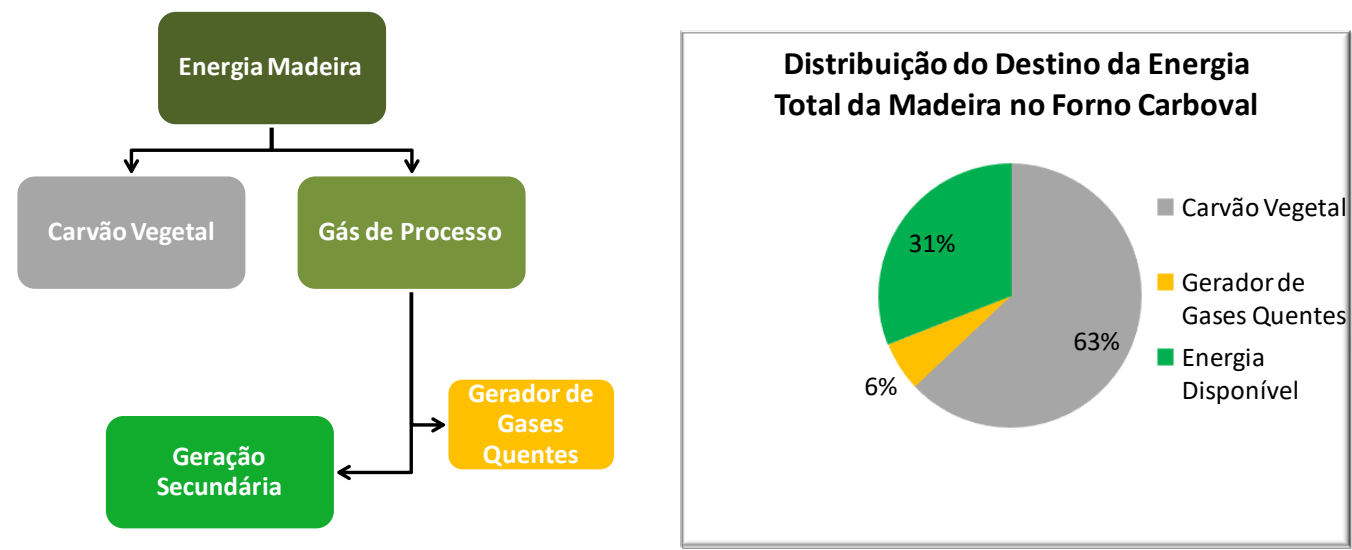

Figura 11 - Distribuição de energia nos Fornos Carboval 


\section{CONCLUSÃO}

Os sistemas de produção de carvão vegetal em fornos convencionais de alvenaria aproximam-se do seu limite técnico e econômico. Para atender às novas demandas, diferentes soluções são necessárias.

Os esforços e investimentos entre os anos de 2008 e 2015 da Vallourec para desenvolver um novo e moderno processo industrial para aproveitamento integral da energia contida na madeira foi alcançado com a Carboval. Esta tecnologia permite a produção do carvão vegetal siderúrgico e cogeração de energia de forma sustentável.

Os principais parâmetros da carbonização, como umidade da madeira, taxa de aquecimento e temperatura de carbonização foram controlados e automatizados. Este controle permitiu a visão de desenvolvimento das novas gerações de biomassa para energia. Ao longo desse período foram produzidas e testadas em Altos Fornos, 32 mil t de carvão vegetal, sendo consumidas diversas espécies de Eucalyptus.

Com o controle e automação e ampliação da escala de produção, a tecnologia Carboval permite a cogeração de energia_adicionando valor e elevando a eficiência deste sistema. A termogeração aproveita todos os resíduos de biomassa da floresta em conjunto com o excesso de energia contida nos gases e bio-óleo produzidos pelo reator. Esta visão holística da produção de carvão vegetal traz uma redução expressiva de custos através da receita com venda de energia elétrica.

\section{REFERÊNCIAS}

1 PINHEIRO, P. C. C. et al. A produção de carvão vegetal: teoria e prática. Belo Horizonte, 2006

2 GOMES, P.A. Teoria da carbonização da madeira, / Paulo Aguinélio Gomes e Joffre Batista de Oliveira. CETEC. In: Uso da madeira para fins energéticos, $1 \mathrm{v}$. 158p. Belo Horizonte: Série Publicações Técnicas 1, 1980.

3 IBÁ - INDÚSTRIA BRASILEIRA DE ÁRVORES. Anuário 2014 - Brasília, 2014. $100 \mathrm{p}$.

4 UNFCCC - UNITED NATIONS FRAMEWORK CONVENTION ON CLIMATE CHANGE. Approved baseline and monitoring methodology AM0041 "Mitigation of methane emissions in the wood carbonization activity for charcoal prodution": version $2006.263 p .6$ Disponível http://www.mct.gov.br/upd_blob/0014/14282.pdf 